\title{
Rotational Seismology Workshop of February 2006
}

By John R. Evans ${ }^{1}$, A. Cochard ${ }^{2}$, Vladimir Graizer ${ }^{3}$, Bor-Shouh Huang ${ }^{4}$, Kenneth W. Hudnut ${ }^{5}$, Charles R. Hutt ${ }^{6}$, H. Igel ${ }^{2}$, William H.K. Lee ${ }^{1}$, Chun-Chi Liu ${ }^{4}$, Eugeniusz Majewski ${ }^{7}$, Robert Nigbor ${ }^{8}$, Erdal Safak $^{9}$, William U. Savage ${ }^{1}$, U. Schreiber ${ }^{10}$, Roman Teisseyre ${ }^{7}$, Mihailo Trifunac ${ }^{11}$, J. Wassermann ${ }^{2}$, and Chien-Fu Wu ${ }^{12}$ (alphabetical throughout, excepting first author here)

${ }^{1}$ U.S. Geological Survey, Menlo Park CA 94025, USA

${ }^{2}$ Sektion Geophysik, Ludwig-Maximilians-Universität, D-80333 München, Germany

${ }^{3}$ California Geological Survey, Sacramento CA 95814, USA

${ }^{4}$ Institute of Earth Sciences, Academia Sinica, Taipei, Taiwan

${ }^{5}$ U.S. Geological Survey, Pasadena CA 91106, USA

${ }^{6}$ U.S. Geological Survey, Albuquerque NM 87198, USA

${ }^{7}$ Institute of Geophysics, Polish Academy of Sciences, 01-452 Warszawa, Poland

${ }^{8}$ Department of Civil Engineering, University of California, Los Angeles CA 90095, USA

${ }^{9}$ Bogazici University, Kandilli Observatory, 81220 Cengelkoy, Istanbul, Turkey

${ }^{10}$ Fundamentalstation Wettzell, Technische Universität München, D-93444 Kötzting, Germany

${ }^{11}$ Department of Civil Engineering, University of Southern California, Los Angeles CA 90089, USA

${ }^{12}$ Seismology Center, Central Weather Bureau, Taipei, Taiwan

2007

Open-file Report 2007-1145 


\section{U.S. Department of the Interior \\ DIRK KEMPTHORNE, Secretary}

\section{U.S. Geological Survey \\ Mark D. Myers, Director}

\section{U.S. Geological Survey, Reston, Virginia 2007}

For product and ordering information:

World Wide Web: http://www.usgs.gov/pubprod

Telephone: 1-888-ASK-USGS

For more information on the USGS - the Federal source for science about the Earth, its natural and living resources, natural hazards, and the environment:

World Wide Web: http://www.usgs.gov

Telephone: 1-888-ASK-USGS

Suggested citation:

Evans, J.R., Cochard, A., Graizer, Vladimir, Huang, Bor-Shouh, Hudnut, Kenneth W., Hutt, Charles R., Igel, H., Lee, William H.K., Liu, Chun-Chi, Majewski, Eugeniusz, Nigbor, Robert, Safak, Erdal, Savage, William U., Schreiber, U., Teisseyre, Roman, Trifunac, Mihailo, Wassermann, J., and, Wu, Chien-Fu, 2007, Rotational seismology workshop of February 2006: U.S. Geological Survey, Open-File Report. 2007-1145, 20 p. [http://pubs.usgs.gov/of/2007/1145/].

Any use of trade, product, or firm names is for descriptive purposes only and does not imply endorsement by the U.S. Government.

Although this report is in the public domain, permission must be secured from the individual copyright owners to reproduce any copyrighted material contained within this report. 


\section{Contents}

Introduction

Theoretical Basis for Rotational Effects in Strong Motion and Some Results

- V. Graizer, E. Safak, and M. D. Trifunac. 6

Observational Experience with Rotational Strong Motion

- B. S. Huang, W. H. K. Lee, C. C. Liu, R. Nigbor, and C. F. Wu.

Integrating GPS, Rotational, and Inertial Sensors

- K. Hudnut...

Teleseismic Rotational Seismology

- A. Cochard, H. Igel, E. Majewski, U. Schreiber, R. Teisseyre, J. Wassermann.

Instrument Testing

- J. R. Evans and C. R. Hutt

Discussion and Conclusions

- W. U. Savage. 16

References

Appendix. A Workshop on Measuring the Rotation Effects of Strong Ground Motion on

16 February 2006 


\section{Rotational Seismology Workshop of February 2006}

By John R. Evans, A. Cochard, Vladimir Graizer, Bor-Shouh Huang, Kenneth W. Hudnut, Charles R. Hutt, H. Igel, William H.K. Lee, Chun-Chi Liu, Eugeniusz Majewski, Robert Nigbor, Erdal Safak, William U. Savage, U. Schreiber, Roman Teisseyre, Mihailo Trifunac, J. Wassermann, and Chien-Fu Wu

\section{Introduction}

A successful workshop titled "Measuring the Rotation Effects of Strong Ground Motion" was held simultaneously in Menlo Park and Pasadena via video conference on 16 February 2006. The purpose of the Workshop and this Report are to summarize existing data and theory and to explore future challenges for rotational seismology, including free-field strong motion, structural strong motion, and teleseismic motions. We also forged a consensus on the plan of work to be pursued by this international group in the near term.

At this first workshop were 16 participants in Menlo Park, 13 in Pasadena, and a few on the telephone. It was organized by William H. K. Lee and John R. Evans and chaired by William U. Savage in Menlo Park and by Kenneth W. Hudnut in Pasadena. Its agenda is given in the Appendix.

This workshop and efforts in Europe led to the creation of the International Working Group on Rotational Seismology (IWGoRS), an international volunteer group providing forums for exchange of ideas and data as well as hosting a series of Workshops and Special Sessions.

IWGoRS created a Web site, backed by an FTP site, for distribution of materials related to rotational seismology. At present, the FTP site contains the 2006 Workshop agenda (also given in the Appendix below) and its PowerPoint ${ }^{\mathrm{TM}}$ presentations, as well as many papers (reasonableonly basis with permission of their authors), a comprehensive citations list, and related information. Eventually, the Web site will become the sole authoritative source for IWGoRS and shared information:

http://www.rotational-seismology.org

ftp://ehzftp.wr.usgs.gov/jrevans/IWGoRS_FTPsite/

With contributions from various authors during and after the 2006 Workshop, this Report proceeds from the theoretical bases for making rotational measurements (Graizer, Safak, Trifunac) through the available observations (Huang, Lee, Liu, Nigbor), proposed suites of measurements (Hudnut), a discussion of broadband teleseismic rotational seismology (Cochard, Igel, Schreiber, Teisseyre, Wassermann, Majewski), sensor-calibration issues (Evans, Hutt), and finally the summary and conclusions (Savage).

As a direct result of the 2006 Workshop and the formation of IWGoRS, we held a special session at the Fall 2006 AGU meeting (convened by H. Igel, W. H. K. Lee, and

M. I. Todorovska). Currently, the first formal Workshop of the IWGoRS is being organized by W. H. K. Lee, M. Çelebi, and M. I. Todorovska with sponsorship by the USGS and assistance from many others; this First International Workshop on Rotational Seismology and Engineering Applications will be held in September 2007 at Menlo Park, California (http://pubs.usgs.gov/of/2007/1145/). 
The following summarizes presentations and discussions during and shortly after the informal Workshop of February 2006. 


\section{Theoretical Basis for Rotational Effects in Strong Motion and Some Results - V. Graizer, E. Safak, and M. D. Trifunac}

In traditional earthquake engineering, structures are designed to resist only simplified representations of strong ground motions - horizontal translational accelerations. Occasionally, the vertical component of linear excitation also may be considered, however rotational excitation by torsional and rocking components is almost never considered.

Recognition that the rocking is caused not only by soil compliance (soil-structure interaction) but also by the rocking of foundations caused by the passage of $P, S V$, and Rayleigh waves began to appear in the mid-1980s (Trifunac, 1982; Castellani and Bofi, 1986, 1989; Lee and Trifunac, 1987; Graizer, 1989). Many studies showed the significance of rocking excitations for both contiguous and base-isolated structures (e.g., Todorovska and Trifunac, 1990a,b; 1992a,b; Todorovska and Trifunac, 1993). Separating the effects of rotational excitation from rocking associated with soil-structure interaction is essential for interpreting observed inter-story drift. Current instrumentation does not permit this separation even approximately (Trifunac et al., 2001). For buildings with large floor plans, warping and deformation of the foundation (Trifunac et al., 1999), and differential translation and rotation complicate both recording and analysis of structural response. Further work is needed in this area before the role of rocking excitation can be understood and included in engineering design.

In the absence of recorded rotational components of strong motion, it is important for engineering studies of response to have at least preliminary, physically realistic simulations of such motions. The method of Lee and Trifunac $(1985,1987)$ for generating artificial torsional and rocking accelerograms meets most of these requirements. This method is an exact analytical solution if it is accepted that (1) the motion occurs in a linear elastic, layered half space and (2) that synthetic ground motion can be constructed by superposition of $P, S V$, and Rayleigh waves for rocking (Lee and Trifunac, 1987), and by SH and Love waves for torsion (Lee and Trifunac, 1985). This method has been extended to predict associated strain (Lee, 1990) and curvature over time near the surface (Trifunac, 1990) during the passage of seismic waves.

Simple models have been studied and used to evaluate the effects of torsional excitation (Gupta and Trifunac, 1987, 1989, 1990) and of rocking excitation (Gupta and Trifunac, 1988, 1991), showing that such excitations can be significant. For example, rocking excitation becomes important for tall structures supported by soft soil while torsional excitations can dominate in the response of long and stiff structures supported by soft soils.

Observations of building response to earthquake shaking led to similar findings. For example, for a seven-story, symmetric, reinforced concrete structure torsional response contributed up to $40 \%$ of the motion at the roof (Trifunac and Ivanovic, 2003). Torsional and rocking excitations contributed to significant damage in this building. In another well-studied building, asymmetry of the foundation and strong torsional excitation by surface waves propagating approximately along the longitudinal axis of the building resulted in a large torsional response (Trifunac et al., 2001).

Recording, analysis, and interpretation of the contributions of torsional and rocking excitations to inter-story drift are essential for future development of earthquake-resistant design codes. Without proper consideration of these contributions, observed drifts may erroneously be assumed to result only from relative displacement of structures, leading to false confidence that current design methods are "conservative" (Trifunac and Ivanovic, 2003). 
Rotational motions in structures are generated by both the rotational components of ground shaking and dynamic characteristics (e.g., mass and stiffness distribution) of the structure. Body $P, S V$, Love, and Rayleigh waves are the main sources of rotational excitations. Rayleigh waves cause horizontal-axis rotational excitations at the base of any multi-story building. Love waves can create rotational excitations about vertical axis (i.e., torsion). The significance of rotational excitations varies with the wavelengths and dominant frequencies of surface waves and the foundation geometry and the natural frequencies of the structure. For tall buildings, Rayleighwave induced rotations can create significant " $P-\Delta$ Effects", which are the overturning moments and horizontal shear forces generated by drift and the weight of the offset building.

Mass and stiffness characteristics of structures determine the amounts of rotation in structural components and their connections. These rotations significantly influence the structure's natural frequency, a key parameter in calculation of seismic design forces. In multistory buildings, for example, it is often assumed that the floor slabs remain horizontal, that there are no rotations at beam-column connections. In fact, beam-column connections do rotate, and the amount of rotation is determined by the relative stiffness of beams and columns and the presence of shear walls. Indeed, in a multiple-story building the assumptions of no-rotations versus free-rotations at the beam-column connections can make more than a factor of two difference in the natural frequencies of the structure. Moreover, knowing rotations in a structure (e.g., rotations of beam-column or beam-shearwall connections, or in-plane rotations of floor slabs) allows one to calculate more precisely the distribution of seismic forces among components such as frames and shear walls.

Thus, there is a need for measuring rotational motions during earthquakes, both on the ground and in the structure. Rotational motions are not now measured but calculated by taking differences between measured linear motions at separated sensors. This differencing operation amplifies the noise in the records significantly, particularly for vertical motions.

Most instruments used to record ground motion are pivot-pendulum or linear-pendulum seismographs, velocigraphs, or accelerographs. It is often assumed that these sensors respond only to translational motions. However, Graizer $(1989,2005)$ showed that the differential equation of small oscillations of horizontal pivot-penduli can be written ( 3 = vertical axis):

$$
y_{1}^{\prime \prime}+2 \omega_{1} D_{1} y_{1}^{\prime}+\omega_{1}^{2} y_{1}=-x_{1}^{\prime \prime}+g \psi_{2}-\psi_{3}^{\prime \prime} l_{1}+x_{2}^{\prime \prime} \theta_{1}
$$

where $y_{i}$ is the recorded response of the instrument, $\theta_{i}$ is the angle of pendulum rotation, $l_{i}$ is the length of the pivot-pendulum arm, $y_{i}=\theta_{i} l_{i}$ at the end of the arm, $\omega_{i}$ is the natural frequency, $D_{i}$ is the fraction of critical damping of the ith transducer, $g$ is the acceleration due to gravity oriented vertically, $x_{i}$ " is the linear ground acceleration in ith direction, and ${ }_{i}$ is a rotation angle of the ground surface about axis $x_{i}$. The following are functions of time: $\theta_{i}$ (thus $y_{1}$ ) and $x_{1}$.

For small oscillations of all penduli, the vertical accelerometer is almost insensitive to tilts. Neglecting the cross-axis sensitivity terms, however, the differential equation of the first horizontal pendulum (Eqn. 1) simplifies to

$$
y_{1}^{\prime \prime}+2 \omega_{1} D_{1} y_{1}^{\prime}+\omega_{1}^{2} y_{1}=-x_{1}^{\prime \prime}+g \psi_{2}
$$

while that of the vertical pendulum becomes

$$
y_{3}^{\prime \prime}+2 \omega_{3} D_{3} y_{3}^{\prime}+\omega_{3}^{2} y_{3}=-x_{3}^{\prime \prime}
$$


Thus, in a typical strong-motion tri-axial instrument both horizontal sensors are responding to a combination of horizontal linear accelerations and axial tilts while the vertical sensor is responding almost entirely to linear acceleration.

Tilting of a horizontal accelerometer's base therefore significantly impacts its output. As shown by Graizer $(2005,2006)$, the presence of unknown tilts in a record makes calculation of displacements impossible using only linear-accelerometer data. Consequently, direct methods of displacement calculation from linear acceleration are not applicable to those records. A conservative procedure based on filtering out the low-frequency portion of linear ground motion by Trifunac (1971) and similar methods are the only way to process existing strong-motion data.

A method for evaluating tilts using uncorrected linear accelerograms proposed by Graizer (1989) has been tested in laboratory experiments with various linear accelerometers. The method is based on the difference in the tilt sensitivity between the horizontal and vertical penduli. It was applied to a number of the large-amplitude records, including from the $M_{W}=6.7$ Northridge earthquake of 1994. Residual tilt extracted from the strong-motion record at the Pacoima Dam reached $3.1^{\circ}$ in the $\mathrm{N} 45^{\circ} \mathrm{E}$ direction, in agreement with residual tilt as measured by an electronic level a few days after the earthquake (Shakal et al., 1994). Records from the Northridge earthquake yielded estimated tilt of $2.9^{\circ}$ on the ground floor of a 12-story hotel in Ventura. Processing most of the largest-amplitude records of the Northridge earthquake did not resolve tilting greater than the error of the method, about $0.5^{\circ}$.

Tilt estimates using existing strong-motion records demonstrate the importance of independent measurements of rotations. It may be especially important in recording the seismic response of buildings because structures can have significant rotational components even in cases when the corresponding free-field ground motion is purely translational. 


\section{Observational Experience with Rotational Strong Motion - B. S. Huang, W. H. K. Lee, C. C. Liu, R. Nigbor, and C. F. Wu}

Nigbor (1994) documents early efforts to measure rotational strong ground motion, using the

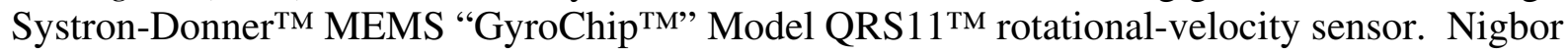
integrated a prototype sensor into his 6-DOF (six degrees of freedom) measurement system. That sensor's range $(0.2 \mathrm{rad} / \mathrm{s}$ full scale and $100 \mu \mathrm{rad} / \mathrm{s}$ resolution) was appropriate for strong ground motions, based on theoretical results of Bouchon and Aki (1982) and others. The system was in the garage of a private home north of Landers, California, $2 \mathrm{~km}$ from the fault trace of the 1992 mainshock. Over two months, six aftershocks were recorded with PGA $\bullet 0.02 \mathrm{~g}$, but no rotational motions were resolved above the $\sim 1 \mathrm{mrad} / \mathrm{s}$ noise level.

However, on 22 September 1993, the Department of Energy conducted a "Non-Proliferation Experiment" (NPE) at the Nevada Test Site, a one-kiloton chemical explosion $390 \mathrm{~m}$ underground. This event was densely monitored by the seismological community (Zucca, 1993); the prototype 6-DOF accelerograph was deployed on bedrock $1 \mathrm{~km}$ from ground zero and successfully recorded viable data on all six sensors, including rotation. Peak rotational velocity was $400 \mathrm{mrad} / \mathrm{s}$, peak linear acceleration $0.8 \mathrm{~g}$ horizontal and $>1 \mathrm{~g}$ vertical.

The rotational sensors then were moved to the surface station of the Borrego Valley Downhole Array in Southern California, where they remain. Since 1994, several hundred earthquakes have been recorded by the BVDA array, with PGA $\bullet 0.2 \mathrm{~g}$, but no rotational motions have been resolved above the $\sim 1 \mathrm{mrad} / \mathrm{s}$ sensor noise.

In 2004, ATA ${ }^{\mathrm{TM}}$ ARS-09TM magneto-hydrodynamic (MHD) rotational-velocity sensors were included in the SFSI (soil-foundation-structure interaction) test structure at the Garner Valley Digital Array in Southern California (part of the George E. Brown, Jr., Network for Earthquake Engineering Simulation; http://nees.ucsb.edu). The rotational sensors are installed on the bottom slab of the $4 \mathrm{~m} \times 4 \mathrm{~m} \times 4 \mathrm{~m}$ test structure, atop soft soil. Four vertical accelerometers in the corners of the foundation slab can be used independently of the ARS-09TM to measure rotational motions. Data from active (shaker) and passive (earthquake and microtremor) monitoring have been gathered for two years. Rocking motion of the structure has been measured using vertical accelerometers, on the order of $100 \mu \mathrm{rad} / \mathrm{s}$, however, no rotational data have been resolved to date above the $\sim 1 \mathrm{mrad} / \mathrm{s}$ rotational-sensor noise.

Lessons from the 13 years of experience with COTS rotational sensors:

- Resolution is $\sim 1 \mathrm{mrad} / \mathrm{s}$ for both the QRS11 $11^{\mathrm{TM}}$ and ATA-09TM

- Small rotational foundation motions can be resolved by closely-spaced vertical accelerometers, but obtaining all axes of motion will be difficult using this method.

- The NEES SFSI test structure at GVDA can be a useful field test site for rotational sensors.

Over the past 13 years Taiwan has begun to monitor the rotational components of strong ground motion in addition to translational acceleration measurements. Interest in rotational strong ground motion derive from theoretical results (Bouchon and Aki, 1982; Lee and Trifunac, 1985). These studies concluded that rotational components of strong ground motion may be important in the near field. Graizer (1989) suggests inertial seismometry methods for weak and strong motions. Estimates of peak rotational velocities in these papers are on the order of $0.1 \mathrm{rad} / \mathrm{s}$, within the range of available inertial sensors. 
The at least 50 near-field strong-motion records from the 1999 Chi-Chi (Taiwan) earthquake indicate that ground motions along the 100-km long rupture are complex and may have included significant rotations. Huang (2003) inferred ground rotational motions of the Chi-Chi earthquake as inferred from dense array observations using the method of Spudich et al. (1995). C. C. Liu and B. S. Huang began recording at 200 sps with triaxial rotation transducers at station HRLT near Hualien on 12 December 2000 (a 12-channel Kinemetrics ${ }^{\mathrm{TM}}$ K2 ${ }^{\mathrm{TM}}$ data logger, an FBA, a PVC-5 $5^{\mathrm{TM}}$ rotation transducer $[0.2 \mathrm{~V} / \mathrm{rad} / \mathrm{s}]$, and a GyroChip ${ }^{\mathrm{TM}}$ rotation transducer $[1.43 \mathrm{~V} / \mathrm{rad} / \mathrm{s}])$. No useful rotation data were obtained after five years of observation. A more sensitive triaxial rotational transducer (eentec/PMD ${ }^{\mathrm{TM}}$ model R-1 ${ }^{\mathrm{TM}}$ ) was purchased and Liu and Huang began observations with it at station HGSD near Cheng-Kung in eastern Taiwan, 07 December 2004. The sensitivity of the R-1 $1^{\mathrm{TM}}$ is $50 \mathrm{~V} / \mathrm{rad} / \mathrm{s}, \sim 35$ times higher than the GyroChip ${ }^{\mathrm{TM}}$ and 250 times higher than the PVC-5 ${ }^{\mathrm{TM}}$. Several hundred earthquakes yielded rotation data during this two-year interval.

At HGSD a six-channel digitizer (Quanterra ${ }^{\mathrm{TM}} \mathrm{Q} 330^{\mathrm{TM}}$ ) is being used to collect data from two sets of sensors: (1) a three-component Guralp ${ }^{\mathrm{TM}}$ CMG-3TD ${ }^{\mathrm{TM}}$ broadband velocity seismometer (down hole at 100-m depth) and (2) the triaxial eentec/PMD ${ }^{\mathrm{TM}}$ model R-1 ${ }^{\mathrm{TM}}$ rotational transducer (at the surface). Data are continuously sampled at 100 sps and 24-bit resolution. At 18:50:20.3 UTC, 26 September 2005, an $M_{W}=5.1$ earthquake occurred $\sim 29 \mathrm{~km}$ south of the station at $23.23^{\circ} \mathrm{N}, 121.40^{\circ} \mathrm{E}$, focal depth $21 \mathrm{~km}$ (CWB Earthquake Report No. 94139). At 17:01:37.2 UTC, 08 January 2006, an $M_{W}=4.6$ earthquake occurred $\sim 36 \mathrm{~km}$ south of the station at $23.16^{\circ} \mathrm{N}, 121.42^{\circ} \mathrm{E}$, focal depth $8.7 \mathrm{~km}$ (CWB Earthquake Report No. 95002). Preliminary observations of peak rotational velocities from these two earthquakes are:

\begin{tabular}{|l|l|l|l|l|}
\hline \multicolumn{1}{|c|}{ Earthquake } & $\begin{array}{c}\text { Epicentral } \\
\text { Distance }(\mathbf{k m})\end{array}$ & \multicolumn{3}{c|}{ Maximum Rotation (prad/s) } \\
Component & & EW & NS & Vertical \\
\hline 26 September 2005 & 29 & 306 & 499 & 1863 \\
\hline 09 January 2006 & 36 & 98 & 183 & 217 \\
\hline
\end{tabular}

A preliminary analyses of these data was performed; these results are described for the 26 September 2005 earthquake. To integrate the rotational velocity data, we first removed their mean and then high-pass filtered with corner at $0.2 \mathrm{~Hz}$ ). Maximum rotation is a few tens of $\mu \mathrm{rad}$ for the horizontal components and about $100 \mu \mathrm{rad}$ for the vertical. Since $1 \mu \mathrm{rad}$ in-plane tilt will introduce about $1 \mu \mathrm{g}$ deflection in a horizontal accelerometer, these results suggest that rotational motions even for an earthquake of $M_{W}=5$ in the middle-field cannot be ignored in double integration of linear acceleration.

Absent to date is in-field calibration of the rotational transducer, so we are not sure that the measurements are real. Also, the deployment also is not optimal; Huang, Lee, Liu, and Wu will deploy additional triaxial rotational transducers (eentec R-1 ${ }^{\mathrm{TM}}$ or PMD ${ }^{\mathrm{TM}} \mathrm{RSB} 20^{\mathrm{TM}}$ ) and accelerometer arrays in two new experiments in Taiwan in 2007 following some calibration tests. 


\section{Integrating GPS, Rotational, and Inertial Sensors - K. Hudnut}

It is fair to say that no one sensor can do everything. Important earthquake-related motions occur over a wide range of amplitudes and periods. Technology evolves quickly, so there is an need to identify promising new devices and develop more capable earthquake-monitoring systems. A single sensor package that measures body and surface waves of teleseisms while also recording near-field strong-motion and permanent displacements is a key goal. GPS and gyros can be important augmentations to weak motion sensors and accelerometers (e.g., Boore, 2003). No site will be well suited to all requirements - quiet across the entire spectrum — and there is complexity in upgrading extant sites. However, there is room for innovation and improvement, particularly in the rapidly developing area known as "inertial-aided GPS".

Technological developments in GPS and inertial measurement units (IMUs) are progressing rapidly. Increasingly, GPS, gyros, and accelerometers are being integrated (the 6-DOF system and GPS covering each other's weaknesses - drift of inertial systems versus obstruction of GPS signals - also providing higher frequency information for anti-skid, dynamic suspension, etc. Cell phones now commonly contain GPS receivers and soon will add inertial sensors. These and other markets have led to rapid improvements in performance while decreasing costs. Algorithms have improved greatly for analyzing real-time data from multiple sensors (e.g., Jekeli, 2001).

The USGS requires such instrumentation for applications like earthquake early warning and fault slip quantification (e.g., for finite-fault source modeling and DamageMap). DamageMap is an automatic, preliminary tagging of structures as red, yellow, or green after a large event, based on the rotations, accelerations, and displacements (drift) of the structure. The DamageMap system is envisioned as a major new product of USGS for urban areas (e.g., Safak and Hudnut, 2006). DamageMap testing has shown that current GPS and accelerometer systems are each inadequate in isolation for recording building motions that translate into structural damage estimates. Torsional and rocking motions are not uniquely measured by GPS or accelerometers, so gyros should be included. Gyros also will improve the redundancy and robustness of DamageMap, fault slip, and early-warning instrument packages. With current ANSS structural instrumentation funding a development and testing program has been initiated for GPS "Point Positioning" and extended "Real-Time Kinematic" GPS methods at the UCLA Factor building; gyros will be purchased and tested shortly. Partly through interactions at this workshop, new ideas went into a new NASA proposal by JPL and USGS, to expand development efforts in support of DamageMap. 


\section{Teleseismic Rotational Seismology-A. Cochard, H. Igel, E. Majewski, U. Schreiber, R. Teisseyre, J. Wassermann}

Recently, precision ring laser technology has been developed for the Earth Sciences, primarily to detect small variations of the Earth's rotation rate. The high resolution of these instruments led to the first measurements of earthquake-induced rotational weak ground motions, first observed at Christchurch, New Zealand (Schreiber et al., 2006). At teleseismic distances the seismic wave field is well approximated by plane waves; in this approximation a direct comparison between rotation rate around a vertical axis and transverse acceleration is possible translations and rotations are in phase and their amplitudes scale by twice the horizontal phase velocity (similar relations hold for strains and translations). A study of collocated translations and rotations has been done with measurements from the $4 \times 4-\mathrm{m}$ ring laser at Wettzell, Germany. These observations showed, over a broad frequency range (1-150 s period), that the waveforms have the expected relationships and that amplitude ratios allow an accurate estimate of horizontal phase velocities (Igel et al., 2005; Cochard et al., 2006). These observations are corroborated by numerical modeling of rotations and translations of the M8.3, Tokachi-oki event, 25 September 2003. A collection of local and distant event records are being accumulated at these sites, which observations led to a purpose-built ring laser system for seismology. One such $2 \times 2$-m prototype is now operational at the Piñon Flat Observatory, California.

In principle, the vertical component of rotation rate can be estimated from seismic array data (e.g., Spudich et al., 1995), but - due to the lack of resolution of rotation sensors - were never compared to direct measurements of rotations. A star-shaped seismic array with an aperture of $3 \mathrm{~km}$ was installed around the ring laser at Wettzell for four months and recorded several large earthquakes. The event recorded with the best signal-to-noise ratio (M6.3, Al Hoceima, 24 February 2004) was modeled with synthetic seismograms; the influence of noise on individual stations were investigated systematically. The results have problems typical when using only a few noisy stations, but a comparison between directly measured rotation rate and array-derived rotations using all nine stations shows they match well (correlation coefficient 0.94). While direct measurements are more practical, this result indicates that accurate smallscale array measurements can be used to test and validate rotational instruments (the method also can be used for rotations around horizontal axes, as vertical components are expected to be less noisy).

Future studies will focus on the estimation of Love-wave dispersion (and other wavefield properties) from collocated measurements of translations and rotations. These new processing tools will be applied to extant events.

Recently, new, sensitive rotation seismographs and laser/fiber ring interferometers (ring laser gyroscopes and fiber optic gyroscopes) exploiting the Sagnac principle have opened new opportunities. Acknowledging that real rotation and twist motions in a source zone exist, there is an open question of how far such fields can propagate from a source as well as unknown rates of attenuation. We should take into account the fact that even distal body and surface seismic waves, when entering a near-surface region characterized by complex structure, may give rise to conjugated microdisplacement motions (cf., microcontinuum theory of composites, porous media, rocks, etc.). That is, rotation and twist waves may again derive from interaction of incident seismic waves with these near-surface features. Theories of micropolar and micromorphic media (Teisseyre, 1973) predict a relationship between displacement derivatives and the microdisplacements. 
Recent experimental and theoretical results for rotational seismic motion motivated creation of a comprehensive monograph (Teisseyre et al., 2006) offering new insights into observations and theory. Teisseyre et al. address many subjects from a variety of viewpoints collected in a manner facilitating systematic coverage. 


\section{Instrument Testing - J. R. Evans and C. R. Hutt}

The Albuquerque Seismological Laboratory (ASL) of the U.S. Geological Survey is being updated with new facilities and capabilities to provide a National testing capability for the ANSS (Advanced National Seismic System), providing ANSS with the ability to verify and maintain a wide variety of sensors, including broadband, strong motion, and perhaps rotational.

ASL is located about 15 miles southeast of Albuquerque, just south of Kirtland AFB on the Isleta Indian Reservation. It is a seismologically quiet site with a large vault consisting of two rooms and a cross tunnel between them, $\sim 15 \mathrm{~m}$ deep in granite. It also has downhole broadband instruments in granite ( 100-200 m) and a set of WWSSN piers on the surface on granite. The underground facilities have excellent long- and short-term temperature stability in addition to noise signatures near the Low Noise Model (Peterson, 1993).

ASL has a series of reference instruments, including an STS-1 ${ }^{\text {TM }}$ in the vault within a superisolated chamber (a sealed, barometric pressure resistant vessel) and both a Geotech ${ }^{\mathrm{TM}}$ KS54000 ${ }^{\mathrm{TM}}$ and a Guralp ${ }^{\mathrm{TM}}$ CMG-3TB ${ }^{\mathrm{TM}}$ downhole (GSN site ANMO). ASL has several Quanterra $^{\mathrm{TM}}$ Q680 ${ }^{\mathrm{TM}}$, high-resolution, 24-bit, 12-channel recorders. Personnel experienced in calibration issues are present, as is software for computing self noise, power spectra, and digital filters, and for performing automated calibration analyses. We have a low-distortion oscillator for testing linearity and distortion in recorders, but this device needs replacement. The facility has one standard Lennartz ${ }^{\mathrm{TM}} /$ Wielandt step table that can be used to calibrate broadband and, perhaps, rotational sensors. ASL has two Russian-made shake tables that may be useful as isolators but would need substantial refurbishment to be useful as shakers and then would probably have too much cross-axis noise for many high-resolution calibration procedures.

Upgrades for proposed ANSS testing include ASL acquisition of: additional low-noise highresolution recorders (either some of the Q680's ${ }^{\mathrm{TM}}$ being retired from GSN or purpose-bought Q330HR's ${ }^{\mathrm{TM}}$, both high-resolution Quanterra ${ }^{\mathrm{TM}}$ recorders); new reference sensors dedicated to calibration and testing (STS-2 ${ }^{\mathrm{TM}}$ and Honeywell ${ }^{\mathrm{TM}}$ QA2000-300 ${ }^{\mathrm{TM}}$ accelerometers). ASL may also acquire an environmental test chamber (temperature \pm humidity \pm pressure), Agilent ${ }^{\mathrm{TM}}$ precision sampling multimeter $\left(3458 \mathrm{~A}^{\mathrm{TM}}\right)$ and dynamic signal analyzer $\left(35670^{\mathrm{TM}}\right)$. A combination of a high-precision tilt table and a high-precision strong-motion shake table would allow for separation of linear and rotational sensitivities and cross-axis sensitivities of both accelerometers and rotational sensors. Additional upgrades may include EMI/RFI/magnetic field generation and test equipment, an additional, larger Lennartz ${ }^{\mathrm{TM}} /$ Wielandt step/tilt table, a new low-distortion oscillator, an interferometric rotational reference sensor, a centrifuge, and new, GUI-based software for standardized testing following ANSS guidelines and those of the Guidelines for Seismometer Testing Workshop (May, 2005, Albuquerque). Finally, it may be appropriate to fit the Russian shake tables as isolation tables and possibly as functioning shake tables.

We note that site noise may also be a limiting factor in the measurement of rotations just as it can be for linear-motion sensors, but we know little about what ambient-noise levels to expect, particularly in urban areas. At quiet sites at least, the best instruments can measure the rotation of the Earth, $72 \mu \mathrm{rad} / \mathrm{s}(0.004 \%)$ as well as the rotational motions associated with large teleseisms. The sensitivity required for strong motion is comparable to the rotational velocity of the Earth. 
Finally, we mention that there has been significant work on the difficult method of measuring rotation by comparing adjacent linear sensors on the same pier (e.g., Huang et al., 2003; Suryanto et al., 2006). 


\section{Discussion and Conclusions - W. U. Savage}

The focus of our general discussion at the Workshop was the immediate future, the near-term after the Workshop. The following comments and suggestions were made.

We agreed to prepare this summary of our deliberations to inform and to include the larger community in subsequent discussions and developments; J. R. Evans and W. H. K. Lee took the lead. We recommend forming an International Working Group to implement our recommendations, to guide future developments, and to help promote theoretical and experimental contributions to the subject of rotational ground motion.

Our consensus for the immediate future is to evaluate existing data and to collect additional data with both current instruments and with new rotational sensors at sites, in structures, and at near-field free-field sites.

The impact of rotational data on engineering design and analysis needs to be explored further, theoretically and through experiments. Prior to a large-scale deployment of rotational sensors, the ultimate societal uses and benefits from expanded measurements should be studied. The Working Groups should review the objectives and benefits of making such measurements.

Additional data are needed to evaluate a wide variety of available sensors and to be certain what is being measured. We should take advantage of both US and international testing and deployment capabilities as well as sensors already owned by any of us. Manufacturers should be invited to participate in development and testing of these systems.

GPS is efficacious in static displacements, with both fact and promise of higher frequency observations. GPS has the advantage of being independent of and complementary to inertial systems. We recommend that GPS be incorporated in ANSS guidance material.

Further evaluation of rotational sensors and rotational measurements can be accelerated by bench testing prior to deployment. These laboratory calibrations would help to verify the data from existing installations. Similarly, field calibration methods must be developed.

Simultaneous measurement of acceleration, rotation, and GPS are needed to sort out tilt from the passage of seismic waves, to certify total displacements, and to broaden the bandwidth of the combined data. GPS is best at long periods while the high-frequency data are also needed and will come primarily from inertial sensors - 1000-Hz GPS is in development but more testing is needed for confident use of high-frequency GPS instrumentation. 


\section{References}

Boore, D. M. (2001). Effect of baseline corrections on displacements and response spectra for several recordings of the 1999 Chi-Chi, Taiwan, earthquake, Bull. Seismol. Soc. Am., 91, no. 5, 1199-1211.

Boore, D. M. (2003). Analog-to-digital conversion as a source of drifts in displacements derived from digital recordings of ground acceleration, Bull. Seismol. Soc. Am., 93, no. 5, 20172024.

Bouchon, M. and K. Aki (1982). Strain, tilt, and rotation associated with strong ground motion in the vicinity of earthquake faults, Bull. Seismol. Soc. Am., 72, 1717-1738.

Castellani, A., and G. Boffi (1986). Rotational components of the surface ground motion during and earthquake, Earthquake Eng. Struct. Dyn., 14, 751-767.

Castellani, A. and G. Boffi (1989). On the rotational components of seismic motion, Earthquake Eng. Struct. Dyn., 18, 785-797.

Cochard, A., H. Igel, A. Flaws, B. Schuberth, J. Wassermann, and W. Suryanto (2006). Rotational motions in seismology, in: Earthquake source asymmetry, structural media and rotation effects, Teisseyre et al., eds., Springer Verlag, Berlin.

Graizer, V. M. (1979). Determination of the true ground displacement by using strong motion records, Izvestiya, Phys. Solid Earth, 15, no. 12, 875-885.

Graizer, V. M. (1989). Bearing on the problem of inertial seismometry, Izvestiya, Phys. Solid Earth, 25, no. 1, 26-29.

Graizer, V. M. (2005). Effect of tilt on strong motion data processing, Soil Dyn. Earthquake Eng., 25, 197-204.

Graizer, V. M. (2006). Equation of Pendulum Motion Including Rotations and its Implications to the Strong-Ground Motion, in Earthquake Source Asymmetry, Structural Media and Rotation Effects, Ed. R. Teisseyre et al., eds., Springer Verlag, Berlin, 471-491.

Gupta, I. D. and M. D. Trifunac (1987). A note on contribution of torsional excitation to earthquake response of simple symmetric buildings, Earthq. Eng. Eng. Vib., 7, no. 3, 2746.

Gupta, I. D. and M. D. Trifunac (1988). A note on computing the contribution of rocking excitation to earthquake response of simple buildings, Bull. Indian Soc. Earthq. Tech., 25, no. 2, 73-89.

Gupta, V. K., and M. D. Trifunac (1989). Investigation of building response to translational and rotational earthquake excitations, Report 89-02, Dept. Civil Eng., Univ. Southern California, Los Angeles, California, U.S.A.

Gupta, V. K. and M. D. Trifunac (1990). Response of multistoried buildings to ground translation and torsion during earthquakes, European Earthq. Eng., IV, no. 1, 34-42.

Gupta, V. K. and M. D. Trifunac (1991). Effects of ground rocking on dynamic response of multistoried buildings during earthquakes, Struct. Eng./Earthq. Eng. (JSCE), 8, no. 2, 4350.

Huang, B. S. (2003). Ground rotational motions of the 1999 Chi-Chi, Taiwan earthquake as inferred from dense array observations, Geophys. Res. Lett., 30, no. 6, 1307.

Igel, H., U. Schreiber, A. Flaws, B. Schuberth, A. Velikoseltsev, and A. Cochard (2005). Rotational motions induced by the M8.1 Tokachi-oki earthquake, September 25, 2003, Geophys. Res. Letters, 32, L08309, doi:10.1029/2004GL022336. 
Iwan, W. D., M. A. Moser, and C.-Y. Peng (1985). Some observations on strong-motion earthquake measurement using a digital accelerograph, Bull. Seismol. Soc. Am., 75, no. 5, $1225-1246$.

Jekeli, C. (2001). Inertial Navigation Systems with Geodetic Applications, Walter de Gruyter, Berlin, 352 pp. (ISBN 3110159031 )

Lee, V. M., and M. D. Trifunac (1985). Torsional accelerograms, Soil Dyn. Earthquake Eng., 4, 132-142.

Lee, V. W. and M. D. Trifunac (1987). Rocking strong earthquake accelerations, Int. J. Soil Dynam. Earthq. Eng., 6, no. 2, 75-89.

Lee, V. W. (1990). Surface strains associated with strong earthquake shaking, Struct. Eng. Earthq. Eng. (JSCE), 422n, no. 1-14, 187-194.

Nigbor, R. L. (1994). Six-degree-of-freedom ground motion measurement, Bull. Seismol. Soc., 84, no. 5, 1665-1669.

Peterson, J. (1993). Observations and modeling of seismic background noise, U.S. Geol. Surv. Open File Rep., 93-322, 94 pp.

Richter, C. F. (1958). Elementary Seismology, W. H. Freeman and Company, San Francisco, $768 \mathrm{pp}$.

Safak, E. and K. Hudnut (2006). Real-time structural monitoring and damage detection by acceleration and GPS sensors, $8^{\text {th }}$ U. S. National Conference on Earthquake Engineering (April 2006 - http://www.1906eqconf.org/), submitted (15 Oct. 2005), 10 pp.

Schreiber, U., G. E. Stedman, H. Igel, A. Flaws (2006). Ring laser gyroscopes as rotations sensors for seismic wave studies, in: Earthquake source asymmetry, structural media and rotation effects, Teisseyre et al., eds., Springer Verlag, Berlin.

Shakal A., T. Cao, and R. Darragh (1994). Processing of the upper left abutment record from Pacoima dam for the Northridge earthquake, Report OSMS, 94-13, Sacramento, 23 p.

Spudich, P., L. K. Steck, M. Hellweg, J. B. Fletcher, and L. M. Baker, Transient stresses at Parkfield, California, produced by the M 7.4 Landers earthquake of June 28, 1992: observations from the UPSAR dense seismograph array, J. Geophys. Res., 100, no. B1, 675-690, 1995.

Suryanto, W., J. Wassermann, H. Igel, A. Cochard, D. Vollmer, F. Scherbaum, A. Velikoseltsev, and U. Schreiber (2006). First comparison of seismic array derived rotations with direct ring laser measurements of rotational ground motion, Bull. Seis. Soc. Am., 96, 20592071.

Teisseyre, R. (1973). Earthquake processes in a micromorphic continuum, Pure Appl. Geophys., 102, 15-28.

Teisseyre, R., M. Takeo, and E. Majewski, eds. (2006). Earthquake Source Asymmetry, Structural Media and Rotation Effects, Springer- Verlag, Berlin.

Todorovska, M. I. and M. D. Trifunac (1990a). Analytical model for building foundation soil interaction: Incident P, SV, and Rayleigh waves, Report 90-01, Dept. of Civil Eng., Univ. of Southern California, Los Angeles, CA.

Todorovska, M. I. and M. D. Trifunac (1990b). A note on the propagation of earthquake waves in buildings with soft first floor, J. Eng. Mech., ASCE, 116, no. 4, 892-900.

Todorovska, M. I. and M. D. Trifunac (1992a). The system damping, the system frequency and the system response peak amplitudes during in-plane building-soil interaction,

Earthquake Eng. and Struct. Dynam., 21, no. 2, 127-144. 
Todorovska, M. I. and M. D. Trifunac (1992b). Effect of input base rocking on the relative response of long buildings on embedded foundations, Eur. Earthq. Eng., VI, no. 1, 3646.

Todorovska, M. I. and M. D. Trifunac (1993). The effects of wave passage on the response of base-isolated buildings on rigid embedded foundations, Report CE 93-10, Dept. of Civil Eng., Univ. of Southern California, Los Angeles, CA.

Trifunac M. D. (1971). Zero baseline correction of strong-motion accelerograms. Bull. Seism. Soc. Am., 61, 1201-1211.

Trifunac, M. D. (1982). A note on rotational components of earthquake motions for incident body waves, Soil Dynamics Earthquake Eng., 1, no. 1, 11-19.

Trifunac, M. D. (1990). Curvograms of strong ground motion, ASCE, J. Eng. Mech. Div., 116, no. $6,1426-1432$.

Trifunac, M. D., S. S. Ivanovic, M. I. Todorovska, E. I. Novikova and A. P. Gladkov (1999). Experimental evidence for flexibility of a building foundation supported by concrete friction piles, Soil Dynamics and Earthquake Eng., 18, (3), 169-187.

Trifunac, M. D., T. Y. Hao and M. I. Todorovska (2001). Response of a 14 story reinforced concrete structure to excitation by nine earthquakes: 61 years of observation in the Hollywood Storage building, Report CE 01-02, Dept. of Civil Eng., Univ. of Southern California, Los Angeles, CA.

Zucca, J. J. (1993). The DOE conducts a non-proliferation experiment at the Nevada Test Site, Eos Trans. AGU, 74, no. 45, 527-527. 10.1029/93EO00678 


\title{
Appendix. A Workshop on Measuring the Rotation Effects of Strong Ground Motion on 16 February 2006
}

\author{
Organized by W. H. K. Lee and John R. Evans
}

(Speaker's name is underlined.)

\section{Workshop Chairs: Woody Savage in Menlo Park and Ken Hudnut in Pasadena}

[Full presentation is allocated 20 minutes for presentation and 5 minutes for discussions]

1:00 p.m. Welcome by Rufus Catchings, Chief Scientist, Western Earthquake Hazard Team

1:05 p.m. Theoretical basis for rotational effects in strong motion and some results. V. Graizer

1:30 p.m. Observational experience with rotational strong motion. $\underline{\text { R. Nigbor }}$

1:55 p.m. Significance of rotational motions in structures. E. Safak

2:00 p.m. Measuring rotation in the free field of Taiwan. W. H. K. Lee, C. C. Liu, and C. F. Wu

2:05 p.m. Plan for instrument testing in the ANSS project. C. R. Hutt and J. R. Evans

2:10 p.m. Discussions for the above three short presentations

2:15 p.m. Break

2:30 p.m. Integrating GPS, strong-motion, and rotation. K. Hudnut

2:55 p.m. Measurement of rotations - conditio sine qua non - for comprehensive interpretation of strong motion. $\underline{\text { M. D. Trifunac }}$

3:20 p.m. A Preliminary Report of Two Taiwan Earthquakes Recorded by Both Broadband and Rotation Sensors. C. C. Liu, B. S. Huang, and W. H. K. Lee

3:40 p.m. General discussion: Recommendations to the community, and action plan. Moderated by R. Nigbor 